\title{
LA GESTIÓN DE LOS DIRECTIVOS Y LA CALIDAD DEL SERVICIO EDUCATIVO DEL COLEGIO SAN ANTONIO MARIANISTAS, BELLAVISTA, REGIÓN CALLAO
}

\author{
THE MANAGEMENT OF THE DIRECTORS AND THE QUALITY OF THE \\ EDUCATIONAL SERVICE OF THE SAN ANTONIO MARIANISTAS SCHOOL, \\ BELLAVISTA, CALLAO REGION
}

\author{
César Augusto CRUZ CÁRDENAS ${ }^{1}$ \\ Ofelia Carmen SANTOS JIMÉNEZ ${ }^{2}$
}

\begin{tabular}{|lll|}
\hline Recibido & $:$ & 30.08 .2020 \\
Aceptado & $:$ & 24.12 .2020 \\
Publicado & $:$ & 12.02 .2021 \\
\hline
\end{tabular}

RESUMEN: Es importante destacar la importancia que cada día cobra el aseguramiento de la calidad educativa a los estudiantes en todos los niveles académicos, siendo más importante aún en la educación básica por lo que la gestión por parte de los responsables de las instituciones académicas debe mantenerse atentos al servicio que brinden, así como la estrategia académica que tengan para cumplir con este principio básico. Por lo mencionado cabe señalar que la presente investigación busca demostrar como la gestión de los directivos se relaciona con la calidad del servicio educativo del colegio San Antonio Marianistas, Bellavista de la Región Callao en el año 2017. Para lo cual se ha recolectado los datos a través de una muestra de 150 estudiantes, 62 docentes, 23 personal administrativo, 90 padres de familia en quienes se empleó una encuesta de opinión utilizando la escala de valor de Likert y para la variable calidad del servicio educativo, se aplicó encuesta a los estudiantes y padres de familia utilizando la escala de nunca, casi nunca, a veces, casi siempre y siempre. Tras el análisis de los resultados se ha evidenciado que existe una relación significativa entre la calidad del servicio a través de una adecuada gestión por parte de los directivos.

Palabras clave: gestión de los directivos, calidad del servicio educativo.

\begin{abstract}
It is important to emphasize the importance that every day becomes the assurance of educational quality to students at all academic levels, being even more important in basic education so that the management by those responsible for academic institutions must remain attentive to the service they provide, as well as the academic strategy they have to meet this basic principle. For this reason, it is important to point out that the present investigation seeks to demonstrate how the management of the directors is related to the quality of the educational service of the San Antonio Marianistas School, Bellavista in the Callao Region in the year 2017. To this end, data has been collected through a sample of 150 students, 62 teachers, 23 administrative personnel, 90 parents in whom an opinion survey was used using the Likert value scale and for the variable quality of the educational service, students and parents were surveyed using the never, almost never, sometimes, almost always and always scale. After the analysis of the results, it has been shown that there is a significant relationship between the quality of the service through adequate management by the directors.
\end{abstract}

Keywords: management of the directors, quality of the educational service.

\footnotetext{
${ }^{1}$ Magister en Educación. Universidad Nacional Mayor de San Marcos-Facultad de Educación. Lima-Perú. Email: cesar_cruz_c@hotmail.com. ORCID: https://orcid.org/0000-0003-3762-862X

2 Doctora en Educación. Universidad Nacional Mayor de San Marcos-Facultad de Educación. Lima-Perú. Email: ofelia.santos@unmsm.edu.pe. ORCID: https://orcid.org/0000-0003-1294-0641
} 


\section{Journal of the Academy | $64 \mid$}

\section{INTRODUCCIÓN}

Nuestro sistema educativo, actualmente se encuentra en un proceso constante de cambio y revaloración, a través de un proyecto nacional hacia 2021, resultando en un estado aun confuso para los actores del sistema educativo, y enfatizando en el área de gestión educativa de la Instituciones Educativas, nos encontramos con ciertos problemas que suscitan preocupaciones, entre ellos el deficiente servicio educativo que brindan algunas instituciones en las diversas áreas del quehacer educativo, académico, administrativo, institucional, etc., siendo una de las principales causas probables el escaso conocimiento y aplicación de una gestión educativa idónea para la realidad de la institución a dirigir.

Asimismo, debemos considerar a la escuela como la unidad de cualquier sistema educativo, se puede afirmar que existe una conciencia creciente de que si queremos mejorar la educación para ello es preciso el cambio o transformación de la escuela, por lo que, bajo estas consideraciones, se ha estimado en estudiar el papel de los directivos y poder dar cuenta del rol que actualmente tienen como gestores de los tan necesarios cambios, de la educación básica.

Por otro lado, comprendemos la necesidad de enfocarse en la gestión del cambio en los directivos claves para lograr el éxito, por ello es necesario que los directivos realicen la toma de decisiones interconectadas entre sí que nos permitirán dejar una situación actual. Gestionar el cambio es, en definitiva, plantear una estrategia que nos ayude a brindar un servicio de calidad en todo ámbito.

La institución en estudio es una comunidad educativa católica que pertenece a la Compañía de María Marianistas en el Perú, busca implementar su propio modelo de gestión del cambio lo cual se considera que es esencial detectar y analizar lo que necesitamos cambiar y, o que elaboremos un plan de cambio, una planificación estratégica que nos indique el camino a seguir para brindar un servicio educativo de calidad.

Al respecto son varios autores los que han trabajado sobre la importancia de la gestión directiva.

Salas \& Lucín (2013) en su trabajo "Evaluación de la calidad del servicio educativo para determinar el nivel de la deserción estudiantil en la Unidad Educativa "Capitán Pedro Oscar Salas Bajaña”. Universidad Católica de Santiago de Guayaquil. Guayaquil, Ecuador se enfocó en evaluar la calidad del servicio educativo para determinar el nivel de deserción estudiantil de 


\section{Journal of the Academy $|65|$}

la unidad educativa "Capitán Pedro Oscar Salas Bajaña” y su repercusión en los servicios educativos entregados.

Por otro lado, Areche (2013) en su trabajo "La Gestión Institucional y la calidad en el servicio educativo según la percepción de los docentes y padres de familia del $3^{\circ}, 4^{\circ}$ y $5^{\circ}$ de secundaria del colegio María Auxiliadora" de Huamanga - Ayacucho 2011, Tesis para optar el Grado Académico de Magister en Educación con mención En Gestión De La Educación, señala la importancia de determinar la medida en la gestión institucional se relaciona con la calidad de los servicios educativos, concluyendo que la existe una relación sustancial entre ambas variables lo que ha permitido la sostenibilidad académicas a los estudiantes.

En ese sentido, el presente trabajo tiene como objetivo demostrar que la gestión de los directivos se relaciona con la calidad del servicio educativo ofrecido por el colegio San Antonio Marianistas. Para lo cual, se ha planteado como hipótesis que estas variables se relacionan significativamente.

Es por ello, que se considera la necesidad de profundizar en la gestión de los directivos como variable independiente, y sus dimensiones como el liderazgo educativo, planificación estratégica, evaluación de la gestión; y, la calidad del servicio educativo como variable dependiente, a través de las dimensiones calidad de los recursos del sistema, de la enseñanza y de los procesos y entornos de aprendizaje; surge la necesidad que tiene el investigador en conocer la implicancia de conocer como la gestión de los directivos dan como consecuencia, cambios significativos en el servicio que brinda la institución educativa a toda la comunidad marianista.

Además, de analizar algunas dificultades que se presentan en el día a día y así dar solución de los problemas periódicas, que tienen su origen en la gestión directiva en forma empírica; sin embargo, con la manejo del método científico se busca dar respuestas a las interrogantes con hechos demostrados que expliquen cuáles son los aspectos más importantes que se deben considerar para brindar un servicio con eficiencia, eficacia y efectividad el servicio educativo que se brinda. 


\section{Journal of the Academy $|66|$}

\section{MARCO TEÓRICO}

La teoría de gestión puede considerarse un cuerpo organizado de los principios y regularidades que existen en el funcionamiento de las organizaciones, lo que se aplica para guiar y prescribir como han de funcionar y como han de ser gestionadas con el propósito de que alcancen mejor eficacia y eficiencia posible. Pearson (2003:67).

Blejamar (2015:20-.37) define la gestión como el proceso de intervenciones para hacer que las cosas sucedan de una determinada manera (ética procesual), sobre la base de propósito ex ante y ex post. La gestión se confronta con resultado, no con objetivos.

Asimismo, para la gestión del centro educativo es el conjunto de acciones de conducción y orientación de los distintos componentes de un centro educativo a ser llevados a cabo, con el fin de lograr objetivos institucionales previstos en el PEI.

Es la capacidad que tiene la comunidad educativa para planificar, organizar, dirigir y evaluar los procesos y recursos de la escuela como soporte de acciones de enseñanza y aprendizaje que se desarrolla en el aula, se pueden distinguir dentro de este, procesos y componentes.

La planificación permite al centro educativo encaminarse por la ruta esperada, hacia el logro de sus fines y objetivos en un período determinado. Así, después de planificar y ejecutar sus actividades y para potenciar su desarrollo y mantenerse esencial de la evaluación institucional es la mejora de la institución evaluada, significando una ayuda importante para la gestión y toma de decisiones.

De esta manera, la evaluación se constituye en un elemento primordial de perfeccionamiento de los centros escolares al incorporarla a los procesos de todo tipo que se producen en ellos y ofrecer los datos suficientes y fiables para aplicar permanentemente las medidas que modifiquen o refuercen lo necesario. 


\section{Journal of the Academy $|67|$}

\section{METODOLOGÍA}

La metodología utilizada para la presente investigación se caracteriza por ser de tipo aplicativo.

Es descriptivo, el tratamiento de los datos empleados tiene un enfoque cuantitativo.

El diseño es correlacional, donde los datos obtenidos de la muestra se esperan determinar el grado de incidencia que tiene la gestión del personal directivo sobre la calidad del servicio educativo de la institución educativa en estudio, el cual es esquematizado en el siguiente Figura:

\section{Figura 1.}

Diagrama de la investigación

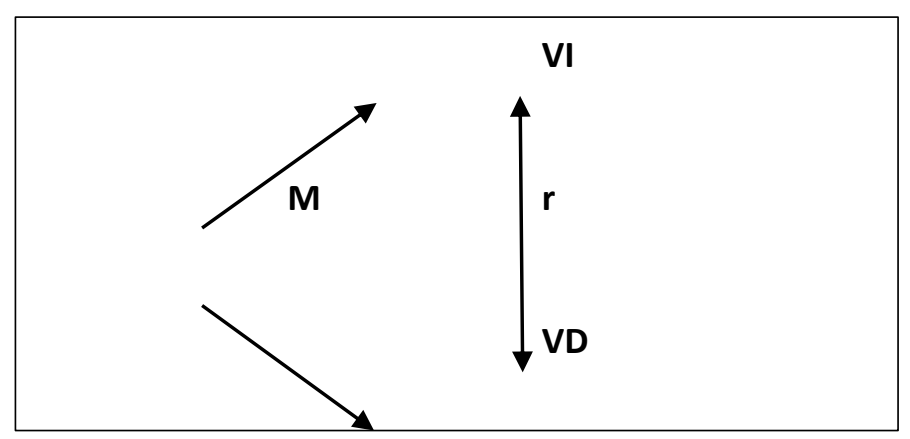

Donde:

M: es la muestra de investigación.

VI: es la variable independiente: gestión del personal directivo.

VD: es la variable dependiente: calidad del servicio educativo

r: $\quad$ es el grado de correlación entre las dos variables.

\section{Población de estudio}

La población de estudio del colegio San Antonio Marianistas, Bellavista Región Callao2017. 


\section{Población}

\begin{tabular}{|l|l|}
\hline ESTRATOS & POBLACIÓN \\
\hline Estudiantes & 1273 \\
\hline Profesores & 113 \\
\hline Directivos & 12 \\
\hline Personal Administrativo & 39 \\
\hline Padres de Familia & 1200 \\
\hline Total & 2627 \\
\hline
\end{tabular}

Nota: Matricula 2017

\section{Análisis de los resultados}

Variable: Gestión de los directivos

Resultados: Directivos

Dimensión 1: Liderazgo Directivo

\section{Tabla $\mathbf{N}^{\circ}$ 1:}

Planificación estratégica

\begin{tabular}{|ll|r|r|r|r|}
\hline & & & \multicolumn{2}{c|}{$\begin{array}{c}\text { Porcentaje } \\
\text { válido }\end{array}$} & $\begin{array}{c}\text { Porcentaje } \\
\text { acumulado }\end{array}$ \\
\hline Válido & NUNCA & Porcentaje & 12,5 & 12,5 \\
& CASI SIEMPRE & 1 & 12,5 & 50,0 & 62,5 \\
& SIEMPRE & 4 & 50,0 & 37,5 & 100,0 \\
& Total & 3 & 37,5 & 100,0 & \\
\hline
\end{tabular}

Fuente: Datos procesados mediante el software SPSS 22 y Excel

\section{Figura $\mathbf{N}^{\circ} 02$}

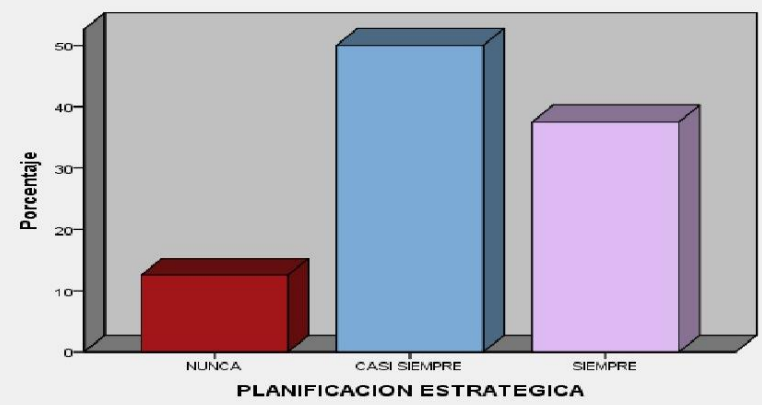




\section{Journal of the Academy | $69 \mid$}

Interpretación: De acuerdo a la tabla estadística y el Figura, se evidencia un total de 08 directivos encuestas señalan que el 25\% de esta dimensión del liderazgo directivo casi nunca, a veces y siempre toma de decisiones y cuentan son estilos de liderazgo, 12,5\% manifiestan que nunca y casi siempre.

\section{Tabla 2:}

\section{Planificación estratégica}

\begin{tabular}{|ll|r|r|r|r|}
\hline & Frecuencia & Porcentaje & \multicolumn{1}{c|}{$\begin{array}{c}\text { Porcentaje } \\
\text { válido }\end{array}$} & \multicolumn{1}{c|}{$\begin{array}{c}\text { Porcentaje } \\
\text { acumulado }\end{array}$} \\
\hline Válido & NUNCA & 1 & 12,5 & 12,5 & 12,5 \\
& CASI SIEMPRE & 4 & 50,0 & 50,0 & 62,5 \\
& SIEMPRE & 3 & 37,5 & 37,5 & 100,0 \\
Total & 8 & 100,0 & 100,0 & \\
\hline
\end{tabular}

Fuente: Datos procesados mediante el software SPSS 22 y Excel

Figura $\mathbf{N}^{\circ} 02$

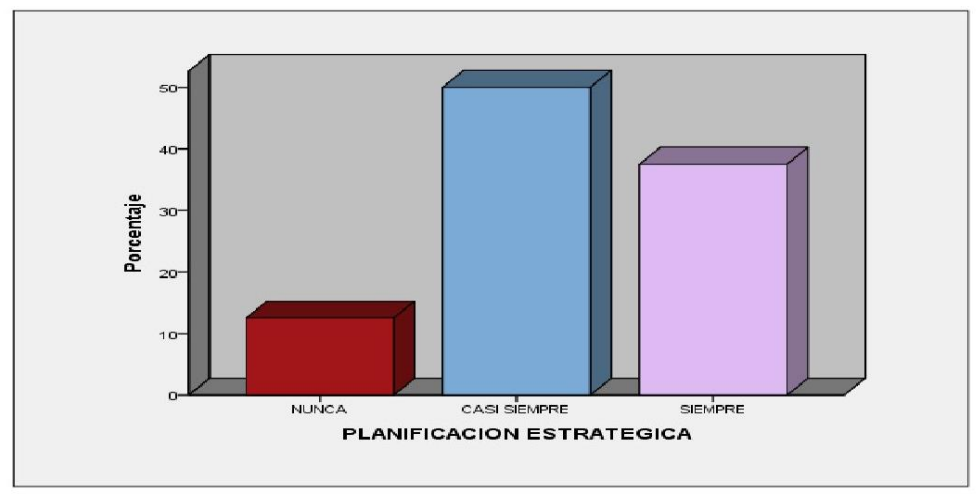

Nota: Elaboración propia

Interpretación: De acuerdo a la tabla estadística y el Figura, se evidencian un total de 08 directivos encuestados señalan que casi siempre el 50\% de esta dimensión de planificación estratégico realizan un diagnóstico, priorizan los problemas y elaboran proyectos, el 37,5\% señalan que siempre y el $12,5 \%$ indican que nunca. 


\section{Tabla 3:}

\section{Evaluación de Gestión}

\begin{tabular}{|ll|r|r|r|r|}
\hline & Frecuencia & Porcentaje & Porcentaje válido & $\begin{array}{r}\text { Porcentaje } \\
\text { acumulado }\end{array}$ \\
\hline Válido & NUNCA & 1 & 12,5 & 12,5 & 12,5 \\
& 1 & 12,5 & 12,5 & 25,0 \\
CASI NUNCA & 3 & 37,5 & 37,5 & 62,5 \\
A VECES & 2 & 25,0 & 25,0 & 87,5 \\
CASI SIEMPRE & 1 & 12,5 & 12,5 & 100,0 \\
SIEMPRE & 8 & 100,0 & 100,0 & \\
Total & 8 & & \\
\hline
\end{tabular}

Fuente: Datos procesados mediante el software SPSS 22 y Excel

\section{Figura $\mathrm{N}^{\circ} 03$}

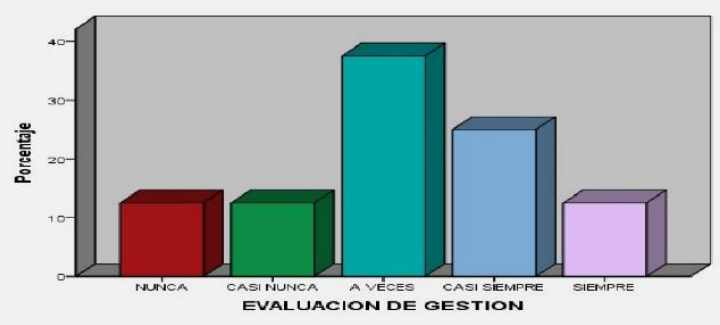

Nota: Elaboración propia

Interpretación: De acuerdo a la tabla estadística y el Figura, se evidencia n total de 08 directivos encuestados señalan que a veces el 37,5\% de esta dimensión de evaluación de gestión cumplen con las metas, evalúan la gestión, evalúan los resultados, el $25 \%$ señalan que casi siempre y el $12,5 \%$ indican que siempre, casi nunca y nunca. 


\section{Journal of the Academy $|71|$}

\section{Tabla 3:}

\section{Convivencia institucional}

\begin{tabular}{|ll|r|r|r|r|}
\hline & Frecuencia & Porcentaje & Porcentaje válido & $\begin{array}{r}\text { Porcentaje } \\
\text { acumulado }\end{array}$ \\
\hline Válido & NUNCA & 3 & 37,5 & 37,5 & 37,5 \\
& CASI NUNCA & 1 & 12,5 & 12,5 & 50,0 \\
A VECES & 1 & 12,5 & 12,5 & 62,5 \\
CASI SIEMPRE & 2 & 25,0 & 25,0 & 87,5 \\
SIEMPRE & 1 & 12,5 & 12,5 & 100,0 \\
Total & 8 & 100,0 & 100,0 & \\
\hline
\end{tabular}

\section{Figura 4}

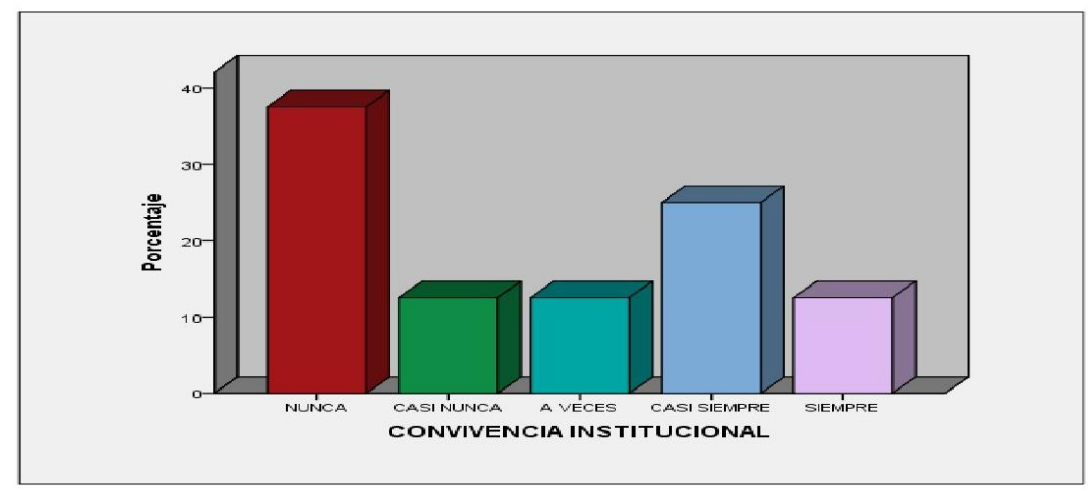

Nota: Elaboración propia

Interpretación: De acuerdo a la tabla estadística y el Figura, se evidencia un total de 08 directivos encuestados señalan que nunca el 37,5\% de esta dimensión de convivencia institucional se tiene buenas relaciones interpersonales y dan solución a conflictos, el 25\% señalan que casi siempre y el $12.5 \%$ indican que siempre, casi nunca y a veces. 


\section{Journal of the Academy $|72|$}

\section{Variable: Gestión de los directivos}

\section{Resultados: Docentes}

Tabla 5:

Liderazgo Directivo

\begin{tabular}{|c|c|c|c|c|c|}
\hline & & Frecuencia & Porcentaje & $\begin{array}{l}\text { Porcentaje } \\
\text { válido }\end{array}$ & $\begin{array}{l}\text { Porcentaje } \\
\text { acumulado }\end{array}$ \\
\hline \multirow[t]{6}{*}{ Válido } & NUNCA & 3 & 4,8 & 4,8 & 4,8 \\
\hline & CASI NUNCA & 13 & 21,0 & 21,0 & 25,8 \\
\hline & A VECES & 15 & 24,2 & 24,2 & 50,0 \\
\hline & CASI SIEMPRE & 16 & 25,8 & 25,8 & 75,8 \\
\hline & SIEMPRE & 15 & 24,2 & 24,2 & 100,0 \\
\hline & Total & 62 & 100,0 & 100,0 & \\
\hline
\end{tabular}

Fuente: Datos procesados mediante el software SPSS 22 y Excel

\section{Figura $\mathbf{N}^{\circ} 05$}

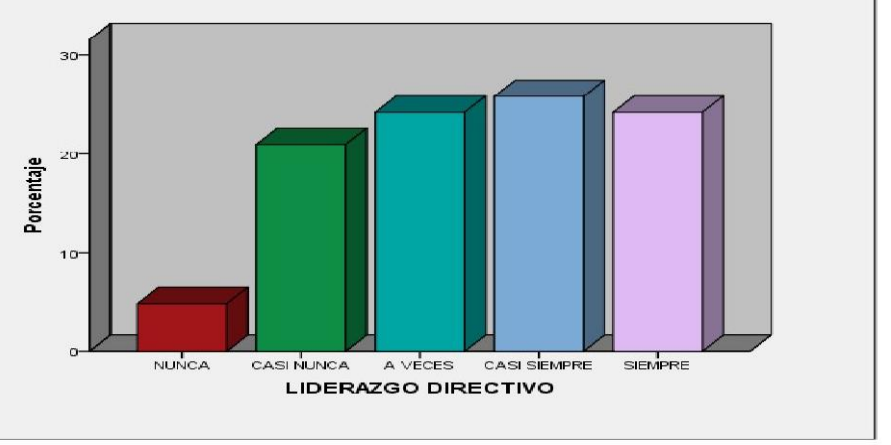

Nota: Elaboración propia

Interpretación: De acuerdo a la tabla estadística y la figura, se evidencia un total de 62 docentes encuestados señalan que el $25,8 \%$ de esta dimensión del liderazgo directivo casi siempre, el $24,2 \%$ a veces y siempre toma de decisiones y cuentan son estilos de liderazgo, el $21,0 \%$ manifiestan que casi nunca y el $4.8 \%$ nunca. 


\section{Journal of the Academy $|73|$}

\section{Tabla 6: Planificación Estratégica}

\begin{tabular}{|ll|r|r|r|r|}
\hline & & \multicolumn{1}{|c|}{ Porcentaje } & \multicolumn{1}{c|}{$\begin{array}{c}\text { Porcentaje } \\
\text { acumulado }\end{array}$} \\
\hline Válido & FuNCA & válido & 6,5 \\
& CASI NUNCA & 4 & 6,5 & 6,5 & 27,4 \\
& 13 & 21,0 & 21,0 & 51,6 \\
A VECES & 15 & 24,2 & 24,2 & 77,4 \\
CASI SIEMPRE & 16 & 25,8 & 25,8 & 100,0 \\
SIEMPRE & 14 & 22,6 & 22,6 & \\
Total & 62 & 100,0 & 100,0 & \\
\hline
\end{tabular}

Fuente: Datos procesados mediante el software SPSS 22 y Excel

\section{Figura $N^{\circ} 06$}

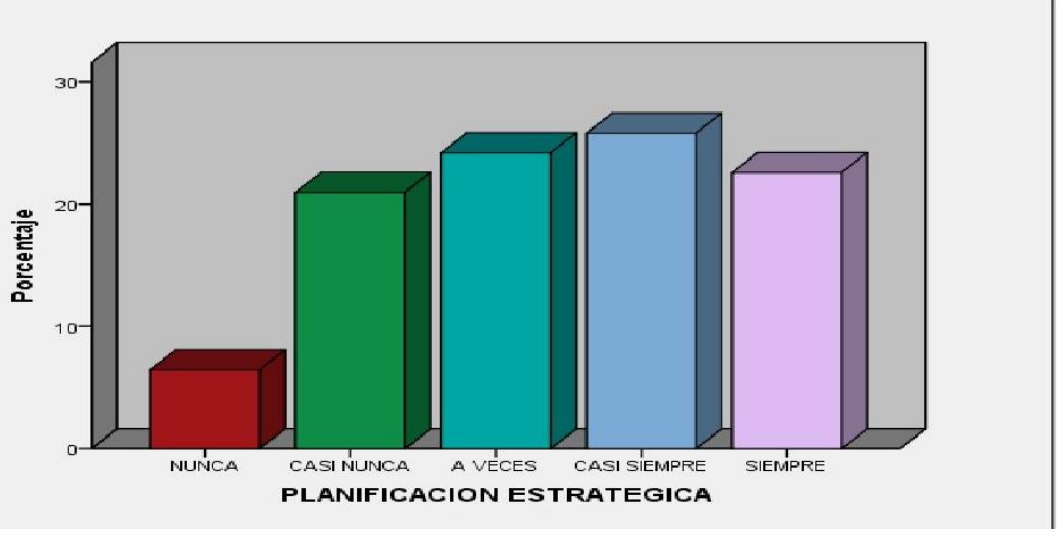

Nota: Elaboración propia

Interpretación: De acuerdo a la tabla estadística y la figura, se evidencia un total de 62 docentes encuestados señalan que casi siempre el 25,8\% de esta dimensión de planificación estratégica realizan un diagnóstico, priorizan los problemas y elaboran proyectos, el $24,2 \%$ señalan que a veces y el 22,6\% indican que siempre, $21,0 \%$ casi nunca el $6.5 \%$ nunca.

\section{Tabla 7:}

\section{Evaluación de Gestión}

\begin{tabular}{|ll|r|r|r|r|}
\hline & Frecuencia & Porcentaje & \multicolumn{2}{c|}{$\begin{array}{c}\text { Porcentaje } \\
\text { válido }\end{array}$} & $\begin{array}{c}\text { Porcentaje } \\
\text { acumulado }\end{array}$ \\
\hline Válido & NUNCA & 7 & 11,3 & 11,3 & 11,3 \\
CASI NUNCA & 11 & 17,7 & 17,7 & 29,0 \\
A VECES & 25 & 40,3 & 40,3 & 69,4 \\
CASI SIEMPRE & 8 & 12,9 & 12,9 & 82,3 \\
SIEMPRE & 11 & 17,7 & 17,7 & 100,0 \\
& & & & \\
Total & 62 & 100,0 & 100,0 & \\
\hline
\end{tabular}




\section{Journal of the Academy $|74|$}

\section{Figura 7}

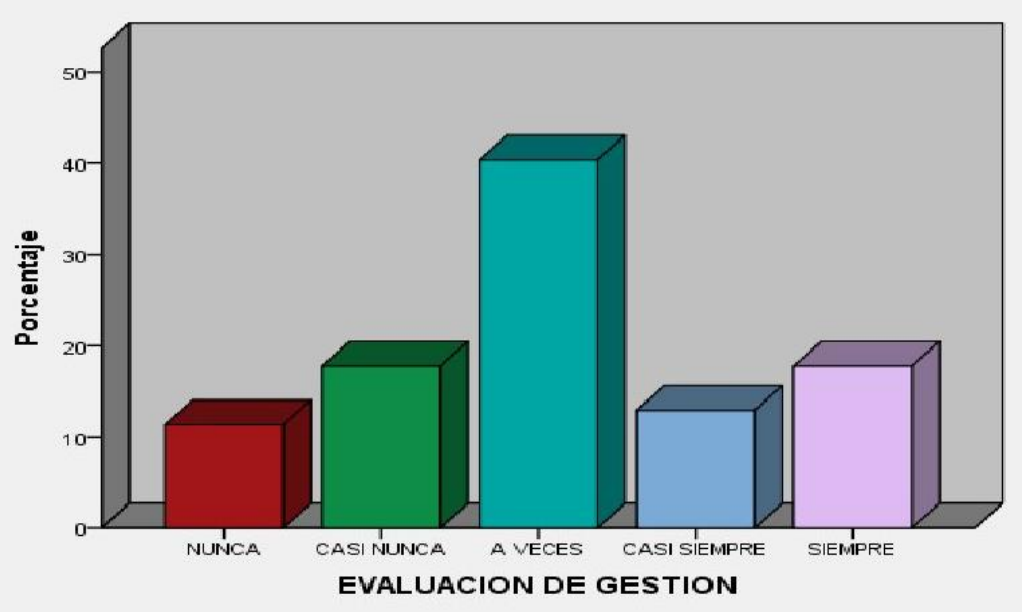

Nota: Elaboración propia

Interpretación: De acuerdo a la tabla estadística y el Figura, se evidencia un total de 62 docentes encuestados señalan que a veces el 40,3\% de esta dimensión de evaluación de gestión cumplen con las metas, evalúan la gestión, evalúan los resultados, el 17,7\% señalan que siempre y casi nunca el $12.9 \%$ indican que casi siempre, el $11.3 \%$ nunca.

\section{Tabla 8:}

\section{Convivencia institucional}

\begin{tabular}{|ll|r|r|r|r|}
\hline & Frecuencia & Porcentaje & \multicolumn{1}{c|}{$\begin{array}{c}\text { Porcentaje } \\
\text { válido }\end{array}$} & $\begin{array}{c}\text { Porcentaje } \\
\text { acumulado }\end{array}$ \\
\hline Válido & NUNCA & 6 & 9,7 & 9,7 & 9,7 \\
& CASI NUNCA & 11 & 17,7 & 17,7 & 27,4 \\
& 24 & 38,7 & 38,7 & 66,1 \\
& A VECES & 13 & 21,0 & 21,0 & 87,1 \\
CASI SIEMPRE & 8 & 12,9 & 12,9 & 100,0 \\
SIEMPRE & 62 & 100,0 & 100,0 & \\
Total & & &
\end{tabular}

Fuente: Datos procesados mediante el software SPSS 22 y Excel 


\section{Journal of the Academy $|75|$}

Figura $N^{\circ} 08$

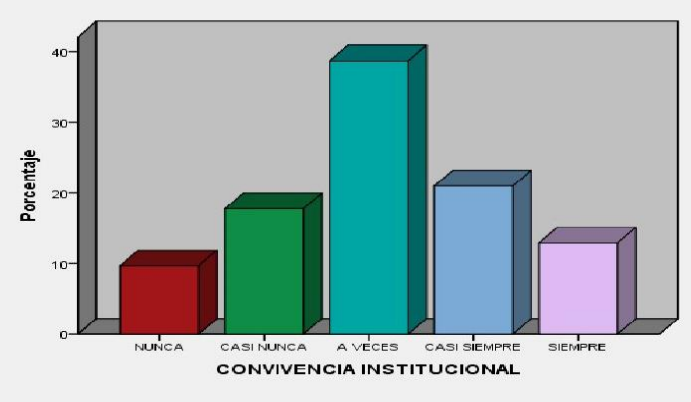

Nota: Elaboración propia

Interpretación: De acuerdo a la tabla estadística y el Figura, se evidencia un total de 62 docentes encuestados señalan que a veces el 38,7\% de esta dimensión de convivencia institucional se tiene buenas relaciones interpersonales y dan solución a conflictos, el $21 \%$ señalan que casi siempre y el $17.7 \%$ indican que casi nunca, el 12,9\% señalan que siempre y el $9,7 \%$ señalan que nunca.

\section{Variable: Gestión de los directivos}

\section{Resultados Administrativos}

\section{Tabla 9:}

\section{Liderazgo directivo}

\begin{tabular}{|ll|r|r|r|r|}
\hline & & & \multicolumn{1}{|c|}{$\begin{array}{c}\text { Porcentaje } \\
\text { válido }\end{array}$} & $\begin{array}{c}\text { Porcentaje } \\
\text { acumulado }\end{array}$ \\
\hline Válido & NUNCA & Porcentaje & 21,7 & 21,7 \\
& CASI NUNCA & 5 & 21,7 & 21,7 & 43,5 \\
& A VECES & 21,7 & 17,4 & 60,9 \\
CASI SIEMPRE & 4 & 17,4 & 30,4 & 91,3 \\
SIEMPRE & 7 & 30,4 & 8,7 & 100,0 \\
& 2 & 8,7 & 100,0 & \\
\hline
\end{tabular}

Fuente: Datos procesados mediante el software SPSS 22 y Excel 


\section{Journal of the Academy $|76|$}

\section{Figura $N^{\circ} 09$}

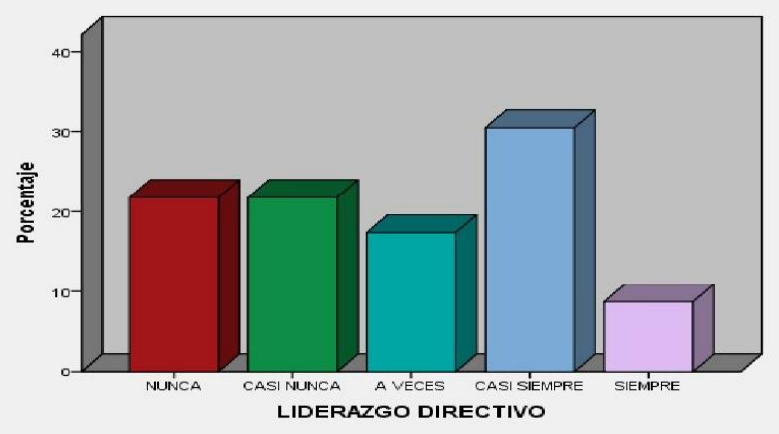

Interpretación: De acuerdo a la tabla estadística y el Figura, se evidencia un total de 23 administrativos encuestados señalan que el 30,4\% de esta dimensión del liderazgo directivo casi siempre, el $21,7 \%$ nunca y casi nunca toma de decisiones y cuentan son estilos de liderazgo, el 17,4\% manifiestan que a veces y el $8,7 \%$ siempre.

\section{Tabla 10:}

\section{Planificación estratégica}

\begin{tabular}{|ll|r|r|r|r|}
\hline & Frecuencia & Porcentaje & \multicolumn{2}{c|}{$\begin{array}{c}\text { Porcentaje } \\
\text { válido }\end{array}$} & $\begin{array}{c}\text { Porcentaje } \\
\text { acumulado }\end{array}$ \\
\hline Válido & NUNCA & 6 & 26,1 & 26,1 & 26,1 \\
& CASI NUNCA & 3 & 13,0 & 13,0 & 39,1 \\
A VECES & 4 & 17,4 & 17,4 & 56,5 \\
CASI SIEMPRE & 2 & 8,7 & 8,7 & 65,2 \\
SIEMPRE & 8 & 34,8 & 34,8 & 100,0 \\
Total & 23 & 100,0 & 100,0 & \\
\hline
\end{tabular}

\section{Figura $\mathbf{N}^{\circ} \mathbf{1 0}$}

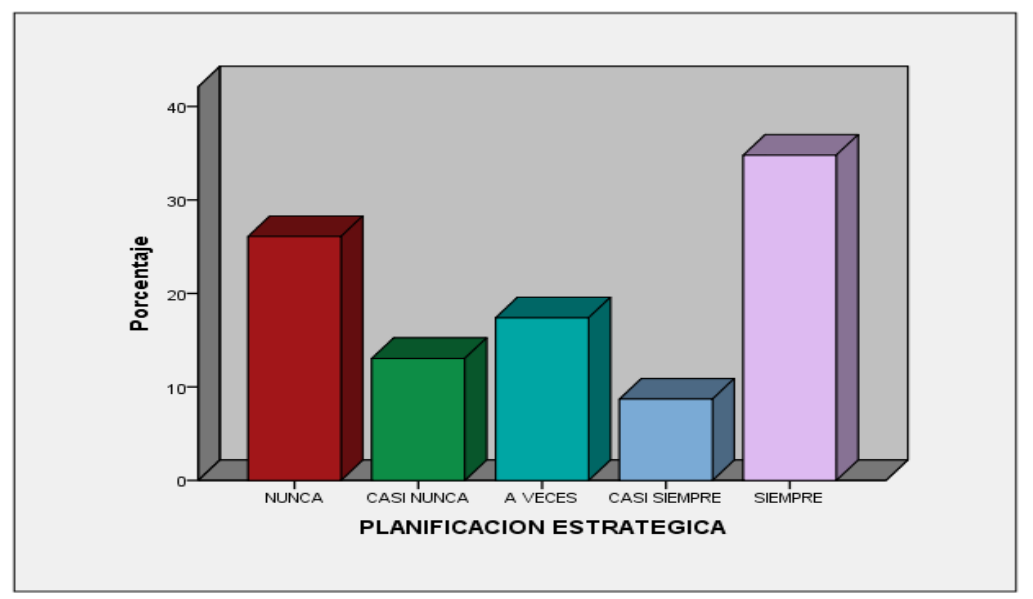




\section{Journal of the Academy $|77|$}

Interpretación: De acuerdo a la tabla estadística y el Figura, se evidencia un total de 23 administrativos encuestados señalan que siempre el 34,8\% de esta dimensión de planificación estratégica realizan un diagnóstico, priorizan los problemas y elaboran proyectos, el $26,1 \%$ señalan que nunca y el 17,4\% indican que a veces, $21,0 \%$ casi nunca el $6.5 \%$ nunca.

\section{Tabla 11:}

Evaluación de Gestión

\begin{tabular}{|ll|r|r|r|r|}
\hline & Frecuencia & Porcentaje & \multicolumn{1}{c|}{$\begin{array}{c}\text { Porcentaje } \\
\text { válido }\end{array}$} & $\begin{array}{c}\text { Porcentaje } \\
\text { acumulado }\end{array}$ \\
\hline Válido & NUNCA & 5 & 21,7 & 21,7 & 21,7 \\
& CASI NUNCA & 2 & 8,7 & 8,7 & 30,4 \\
A VECES & 8 & 34,8 & 34,8 & 65,2 \\
CASI SIEMPRE & 3 & 13,0 & 13,0 & 78,3 \\
SIEMPRE & 5 & 21,7 & 21,7 & 100,0 \\
Total & 23 & 100,0 & 100,0 & \\
\hline
\end{tabular}

\section{Figura $\mathbf{N}^{\circ} 11$}

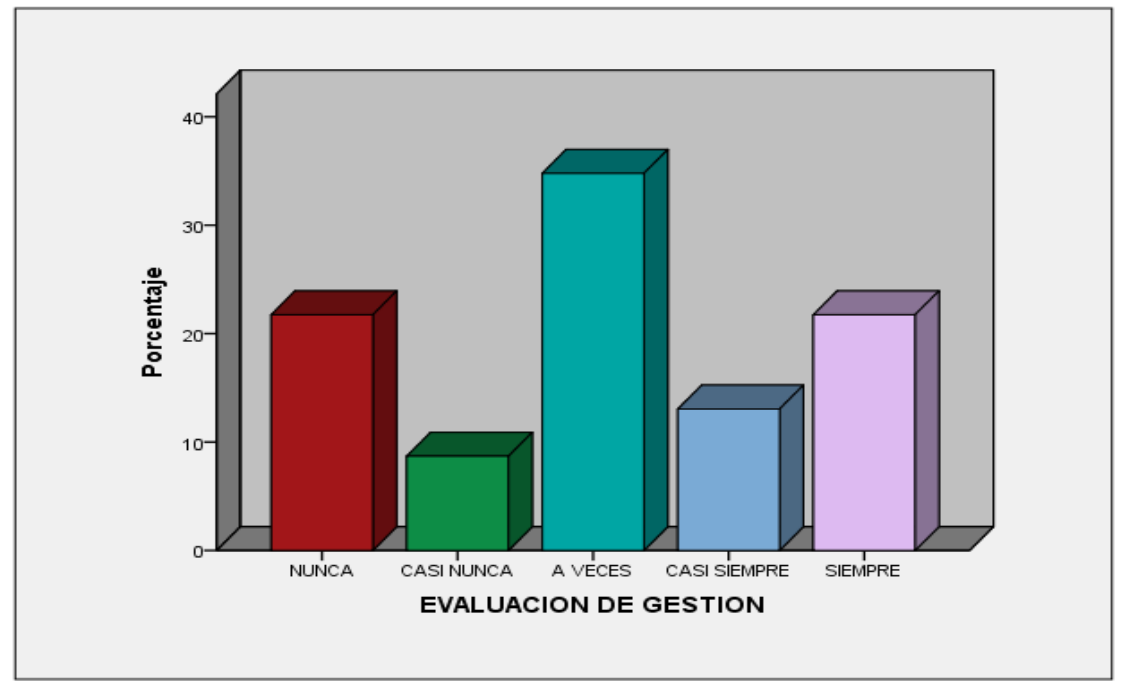

Nota: Elaboración propia 


\section{Journal of the Academy $|78|$}

Interpretación: De acuerdo a la tabla estadística y el Figura, se evidencia un total de 23 administrativos encuestados señalan que a veces el 34,8\% de esta dimensión de planificación estratégica realizan un diagnóstico, priorizan los problemas y elaboran proyectos, el $21,7 \%$ señalan que nunca y siempre, el 13,0\% indican que casi siempre el 8,7\% casi nunca.

\section{Tabla $\mathbf{N}^{\circ}$ 12:}

Convivencia institucional

\begin{tabular}{|l|r|r|r|r|}
\hline & Frecuencia & Porcentaje & \multicolumn{1}{c|}{$\begin{array}{c}\text { Porcentaje } \\
\text { válido }\end{array}$} & $\begin{array}{c}\text { Porcentaje } \\
\text { acumulado }\end{array}$ \\
\hline Válido NUNCA & 5 & 21,7 & 21,7 & 21,7 \\
CASI & 3 & 13,0 & 13,0 & 34,8 \\
NUNCA & 7 & 30,4 & 30,4 & 65,2 \\
A VECES & 1 & 4,3 & 4,3 & 69,6 \\
CASI & 7 & 30,4 & 30,4 & 100,0 \\
SIEMPRE & 23 & 100,0 & 100,0 & \\
SIEMPRE & & & \\
Total & & & & \\
\hline
\end{tabular}

Nota: Datos procesados mediante el software SPSS 22 y Excel

\section{Figura $\mathbf{N}^{\circ} 12$}

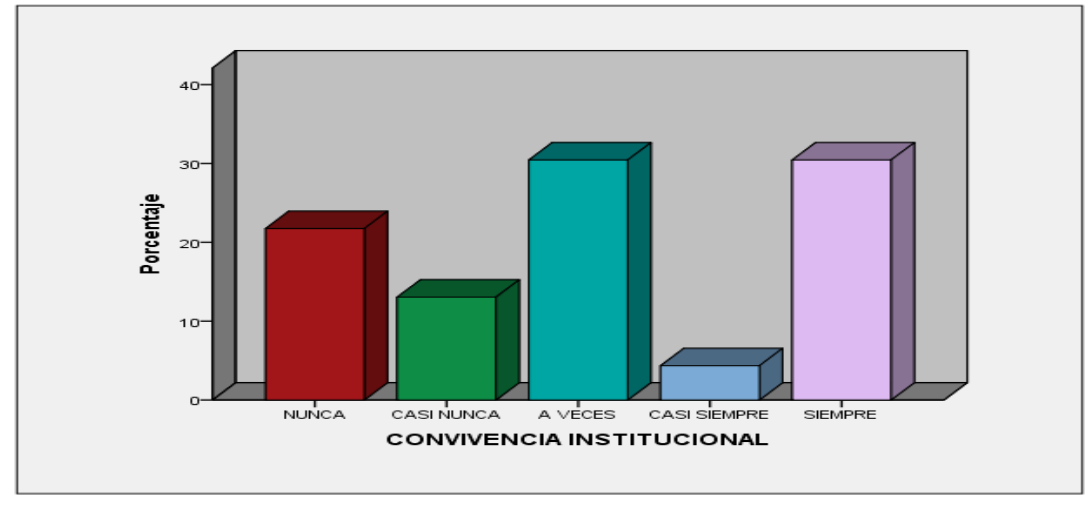

Nota: Elaboración propia 


\section{Journal of the Academy $|79|$}

Interpretación: De acuerdo a la tabla estadística y el Figura, se evidencia un total de 23 administrativos encuestados señalan que a veces y siempre el 30,4\% de esta dimensión de convivencia institucionales tiene buenas relaciones interpersonales y dan solución a conflictos, el $21,7 \%$ señalan que nunca y el 13,0\% indican que casi nunca, el 4,3\% señalan que casi siempre.

\section{Variable dependiente (Y): Calidad del Servicio Educativo}

\section{Resultado: Estudiantes}

Tabla $\mathbf{N}^{\circ}$ 13:

Calidad de los recursos del sistema

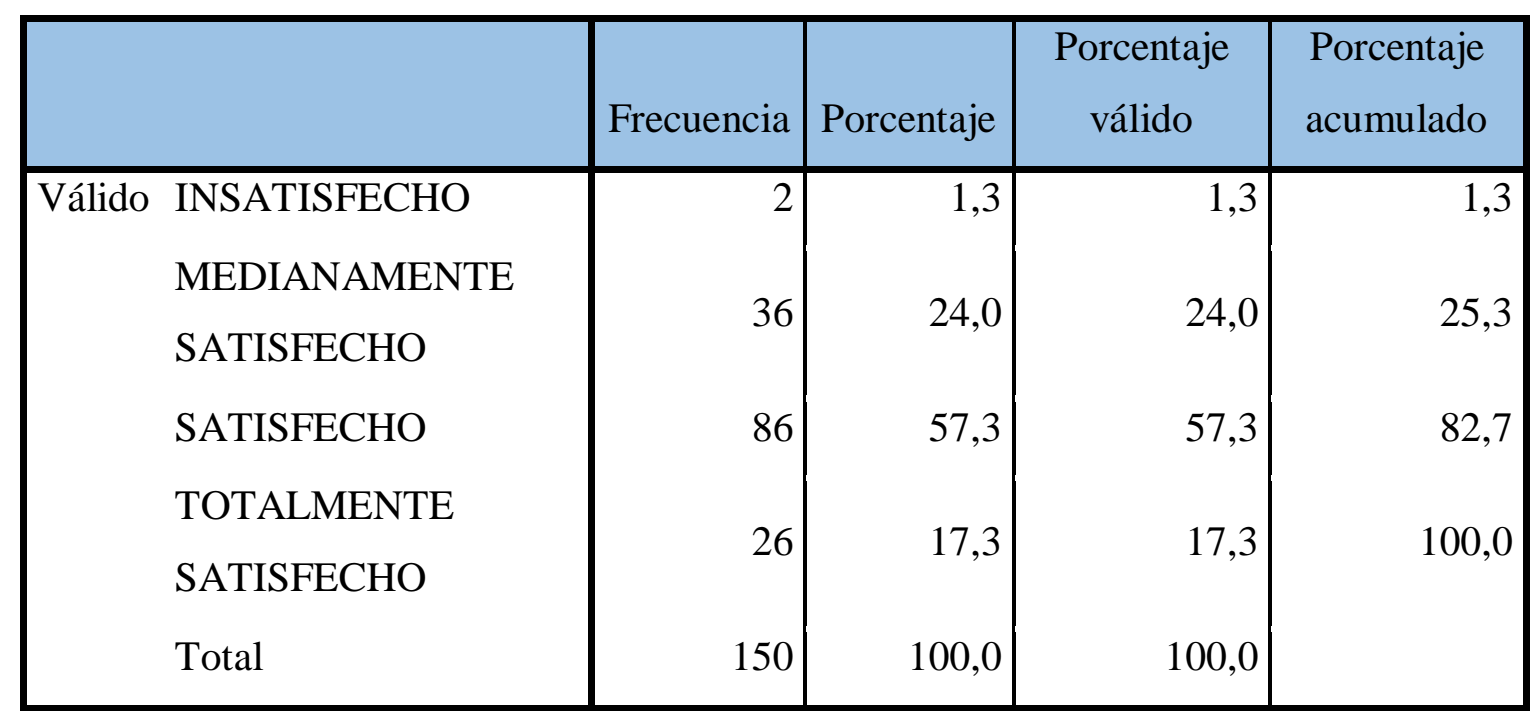

Nota: Datos procesados mediante el software SPSS 22 y Excel 


\section{Figura $\mathbf{N}^{\circ} 13$}

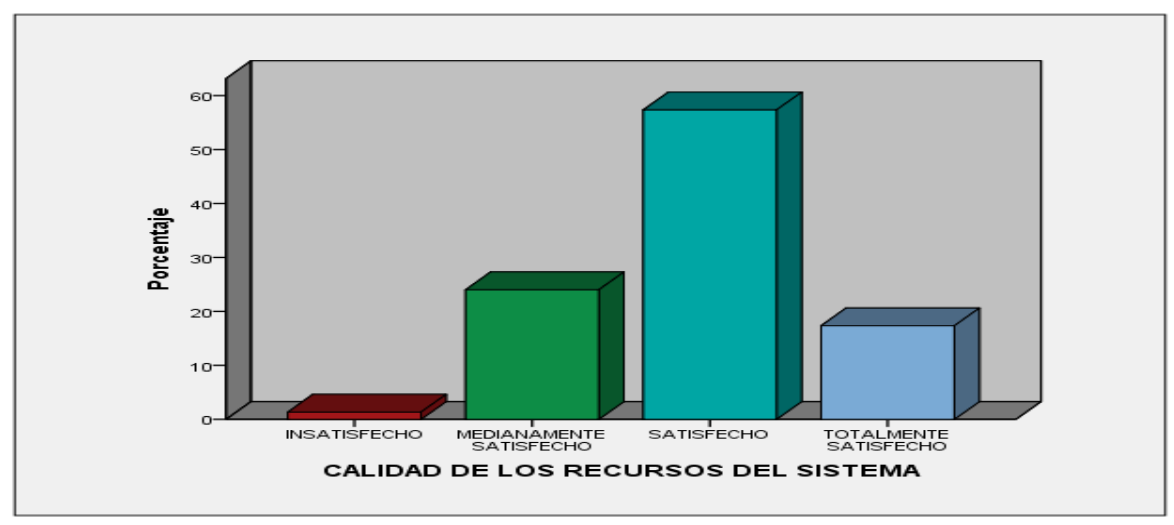

Nota: Elaboración propia

Interpretación: De acuerdo a la tabla estadística y el Figura, se evidencia un total de 150 estudiantes encuestados quienes señalan que el 57,3\% se encuentran satisfecho en infraestructura, materiales y equipos tecnológicos, el 24,0\% se encuentran medianamente satisfecho, el17,3\% totalmente satisfecho y el 1,3\% se encuentra insatisfecho de la calidad de los recursos del sistema.

\section{Tabla $\mathbf{N}^{\circ}$ 14:}

Calidad de la enseñanza

\begin{tabular}{|l|r|r|r|r|}
\hline & Frecuencia & Porcentaje & $\begin{array}{c}\text { Porcentaje } \\
\text { válido }\end{array}$ & $\begin{array}{c}\text { Porcentaje } \\
\text { acumulado }\end{array}$ \\
\hline Válido INSATISFECHO & 9 & 6,0 & 6,0 & 6,0 \\
MEDIANAMENTE & 48 & 32,0 & 32,0 & 38,0 \\
SATISFECHO & 65 & 43,3 & 43,3 & 81,3 \\
SATISFECHO & 28 & 18,7 & 18,7 & 100,0 \\
TOTALMENTE & 150 & 100,0 & 100,0 & \\
SATISFECHO & & & \\
Total & & & & \\
\hline
\end{tabular}

Nota: Datos procesados mediante el software SPSS 22 y Excel 


\section{Journal of the Academy $|81|$}

\section{Figura $\mathbf{N}^{\circ} 14$}

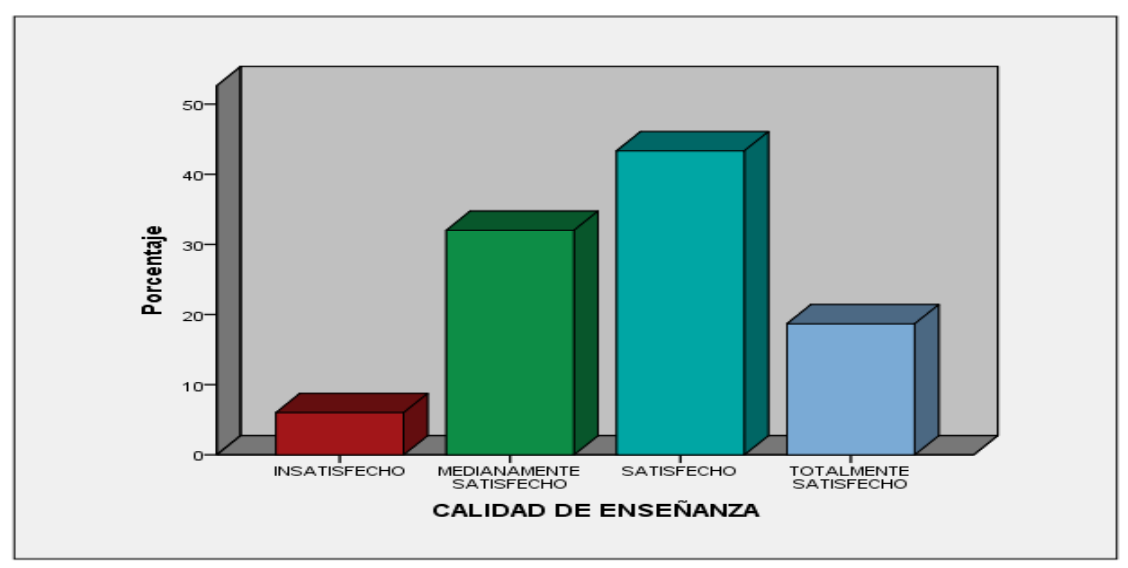

Nota: Elaboración propia

Interpretación: De acuerdo a la tabla estadística y el Figura, se evidencia un total de 150 estudiantes encuestados quienes señalan que el $43,3 \%$ se encuentran satisfecho en la explicación del docente, utilizándolas técnicas, el uso de estrategias, los materiales didácticos, la exposición de temas, la motivación, materiales y equipos tecnológicos, el 32,0\% se encuentran satisfecho, el18, 7\% totalmente satisfecho y el 6\% se encuentra insatisfecho de la calidad de la enseñanza.

Tabla $\mathbf{N}^{\circ}$ 15:

Calidad de los Procesos y Entornos del Aprendizaje

\begin{tabular}{|l|r|r|r|r|}
\hline & Frecuencia & Porcentaje & \multicolumn{1}{c|}{$\begin{array}{c}\text { Porcentaje } \\
\text { válido }\end{array}$} & $\begin{array}{l}\text { Porcentaje } \\
\text { acumulado }\end{array}$ \\
\hline Válido & $\begin{array}{l}\text { INSATISFECHO } \\
\text { MEDIANAMENTE } \\
\text { SATISFECHO }\end{array}$ & 2,7 & 2,7 & 2,7 \\
SATISFECHO & 81 & 54,0 & 54,0 & 22,0 \\
TOTALMENTE & 36 & 24,0 & 24,0 & 10,0 \\
$\begin{array}{l}\text { SATISFECHO } \\
\text { Total }\end{array}$ & 150 & 100,0 & 100,0 & \\
\hline
\end{tabular}

Nota: Datos procesados mediante el software SPSS 22 y Excel 


\section{Journal of the Academy $|82|$}

\section{Figura $\mathbf{N}^{\circ} 15$}

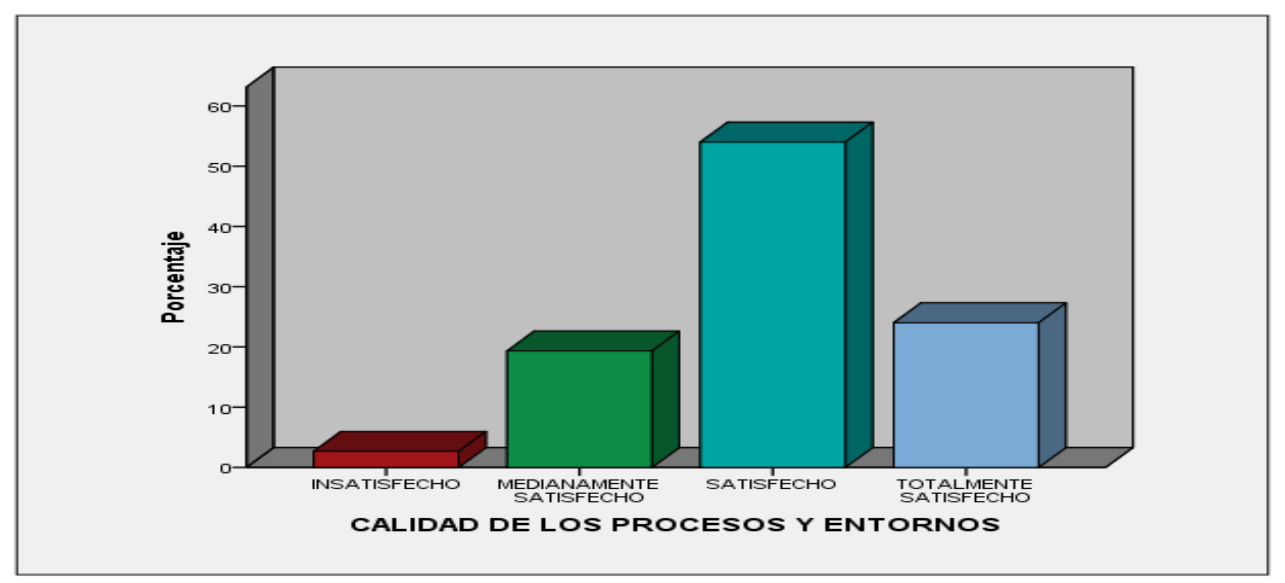

Nota: Elaboración propia

Interpretación: De acuerdo a la tabla estadística y el Figura, se evidencia un total de 150 estudiantes encuestados quienes señalan que el 54,0\% se encuentran satisfecho en la fiabilidad, la garantía y empatía que brinda la institución educativa con respecto a la calidad de enseñanza, el 24,0\% se encuentran totalmente satisfecho, el 19,3\% medianamente satisfecho y el 2,7\% se encuentra insatisfecho de la calidad de los procesos y entornos del aprendizaje.

\section{Tabla $\mathbf{N}^{\circ}$ 16:}

Calidad de los recursos del sistema

\begin{tabular}{|l|l|r|r|r|r|}
\hline \multicolumn{2}{|l|}{} & Frecuencia & Porcentaje & \multicolumn{1}{c|}{$\begin{array}{c}\text { Porcentaje } \\
\text { válido }\end{array}$} & $\begin{array}{l}\text { Porcentaje } \\
\text { acumulado }\end{array}$ \\
\hline Válido & INSATISFECHO & 9 & 10,0 & 10,0 & 10,0 \\
\cline { 2 - 6 } & $\begin{array}{l}\text { MEDIANAMENTE } \\
\text { SATISFECHO }\end{array}$ & 20 & 22,2 & 22,2 & 32,2 \\
\cline { 2 - 6 } & SATISFECHO & 40 & 44,4 & 44,4 & 76,7 \\
\cline { 2 - 6 } & $\begin{array}{l}\text { TOTALMENTE } \\
\text { SATISFECHO }\end{array}$ & 21 & 23,3 & 23,3 & 100,0 \\
\cline { 2 - 6 } & Total & 90 & 100,0 & 100,0 & \\
\hline
\end{tabular}

Nota: Datos procesados mediante el software SPSS 22 y Excel 


\section{Journal of the Academy $|83|$}

\section{Figura $\mathbf{N}^{\circ} 16$}

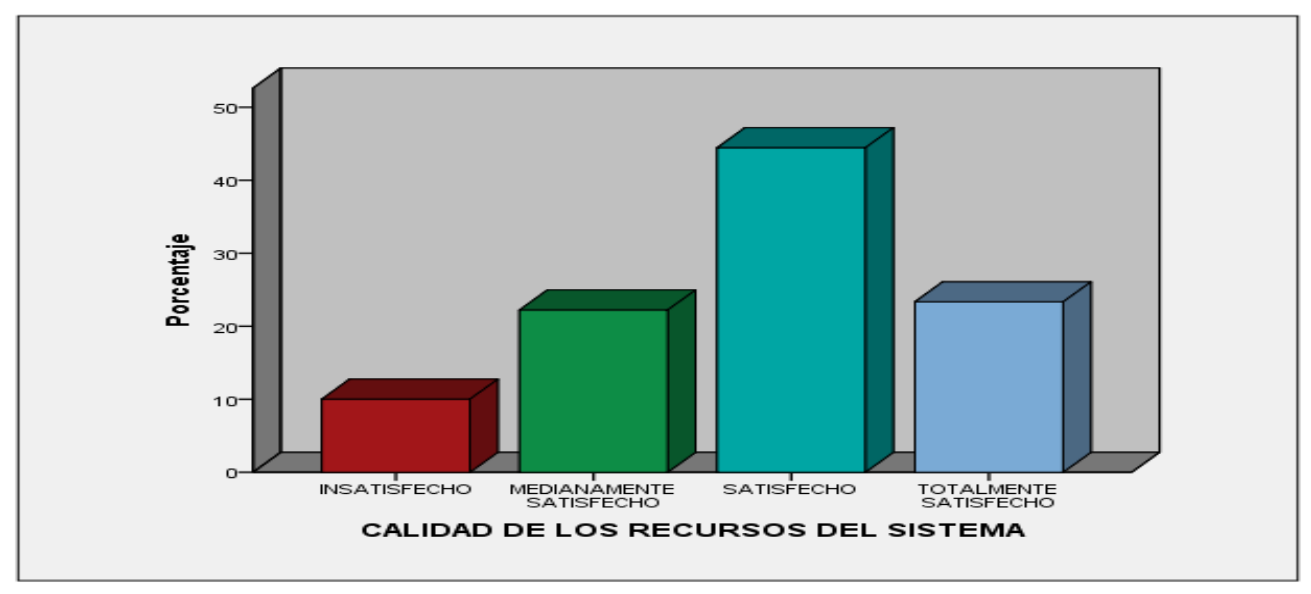

Nota: Elaboración propia

Interpretación: De acuerdo a la tabla estadística y el Figura, se evidencia un total de 90 padres de familia encuestados quienes señalan que el $44,4 \%$ se encuentran satisfecho en infraestructura, materiales y equipos tecnológicos, el 23,3\% se encuentran totalmente satisfecho, el 22,2\% medianamente satisfecho y el 10,0\% se encuentra insatisfecho de la calidad de los recursos del sistema.

\section{Tabla $\mathbf{N}^{\circ}$ 17:}

Calidad de la enseñanza

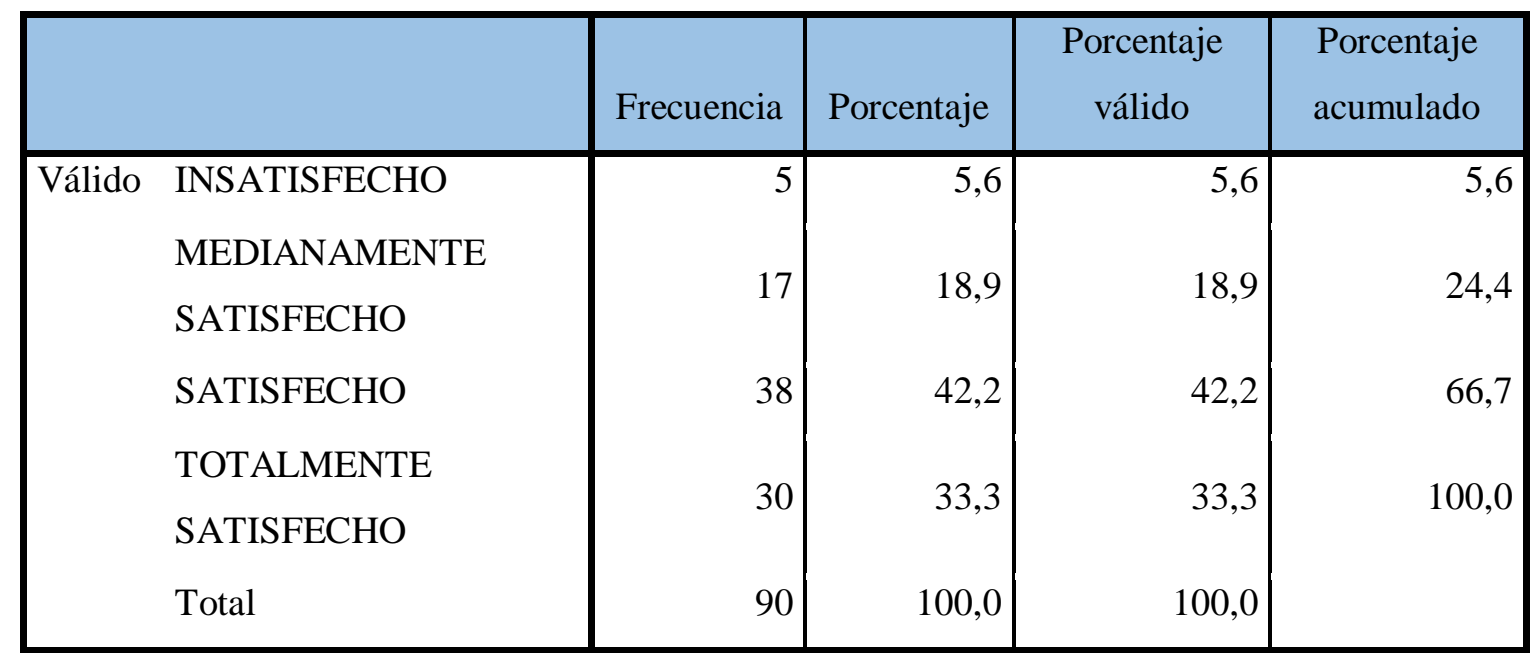

Nota: Datos procesados mediante el software SPSS 22 y Excel 


\section{Journal of the Academy $84 \mid$}

\section{Figura $\mathbf{N}^{\circ} 17$}

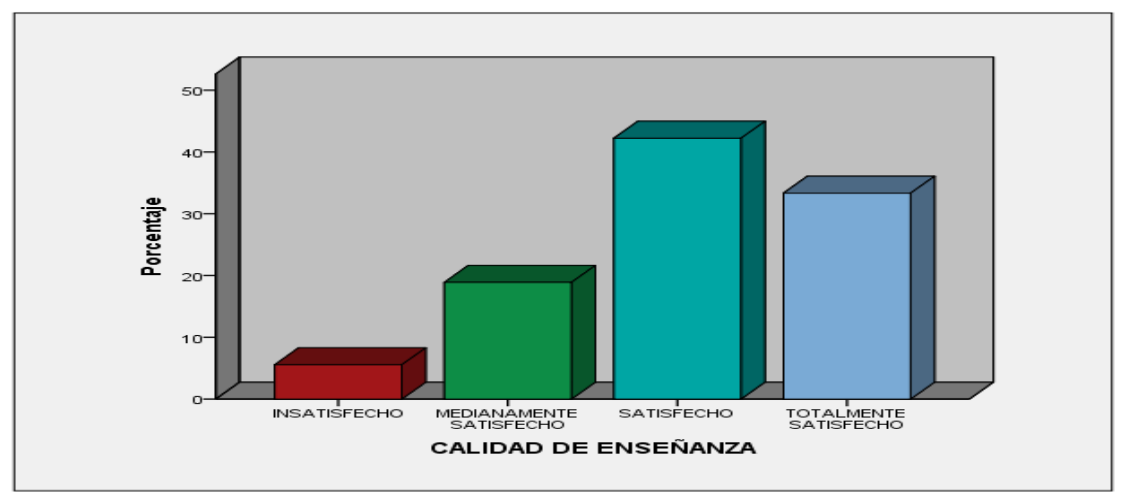

Interpretación: De acuerdo a la tabla estadística y el Figura, se evidencia un total de 90 padres de familia encuestados quienes señalan que el 42,2\% se encuentran satisfecho en la explicación del docente, utilizándolas técnicas, el uso de estrategias, los materiales didácticos, la exposición de temas, la motivación, materiales y equipos tecnológicos, el 33,3\% se encuentran totalmente satisfecho, el18,9\% medianamente satisfecho y el 5,6\% se encuentra insatisfecho de la calidad de la enseñanza.

\section{Resultados: Padres de Familia}

Tabla $\mathbf{N}^{\circ}$ 18:

Calidad de los procesos y entornos del aprendizaje

\begin{tabular}{|c|c|c|c|c|c|}
\hline & & Frecuencia & Porcentaje & $\begin{array}{c}\text { Porcentaje } \\
\text { válido }\end{array}$ & $\begin{array}{l}\text { Porcentaje } \\
\text { acumulado }\end{array}$ \\
\hline \multirow[t]{7}{*}{ Válido } & INSATISFECHO & 7 & 7,8 & 7,8 & 7,8 \\
\hline & MEDIANAMENTE & & & & \\
\hline & SATISFECHO & 18 & 20,0 & 20,0 & 27,8 \\
\hline & SATISFECHO & 45 & 50,0 & 50,0 & 77,8 \\
\hline & TOTALMENTE & 20 & 2 & 27 & 1000 \\
\hline & SATISFECHO & 20 & 22,2 & 22,2 & 100,0 \\
\hline & Total & 90 & 100,0 & 100,0 & \\
\hline
\end{tabular}

Nota: Datos procesados mediante el software SPSS 22 y Excel 


\section{Journal of the Academy $|85|$}

\section{Figura $\mathbf{N}^{\circ} 18$}

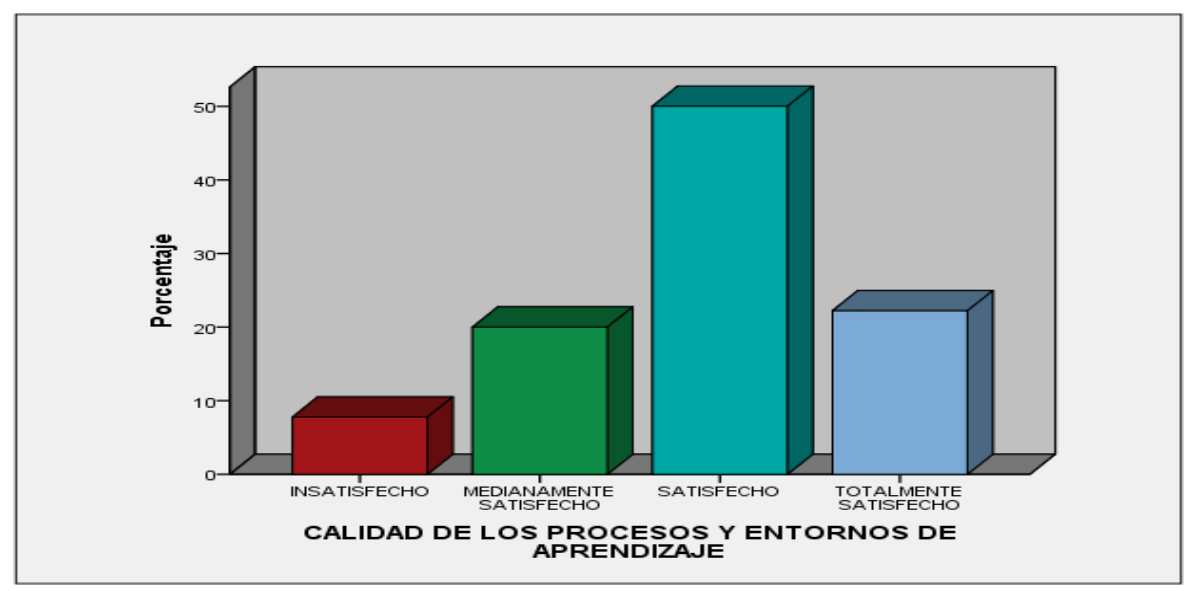

Nota: Elaboración propia

Interpretación: De acuerdo a la tabla estadística y el Figura, se evidencia un total de 90 padres de familia encuestados quienes señalan que el 50,0\% se encuentran satisfecho en la fiabilidad, la garantía y empatía que brinda la institución educativa con respecto a la calidad de enseñanza, el $22,2 \%$ se encuentran totalmente satisfecho, el 20,0\% medianamente satisfecho y el 7,8\% se encuentra insatisfecho de la calidad de los procesos y entornos del aprendizaje.

\section{Resultados}

\section{Contrastación de la hipótesis}

Tras el análisis de los resultados se procede a contrastar la información obtenida con la hipótesis inicialmente planteada:

Ho: La gestión de los directivos no se relaciona o incide de manera significativa con la calidad del servicio educativo.

Ha: La gestión de los directivos relaciona o incide de manera significativa con la calidad del servicio educativo.

Estas hipótesis se plantean bajo la regla teórica: Si el valor $\mathrm{p} \geq 0.05$ se Acepta la hipótesis Nula (Ho). Si el valor $\mathrm{p}<0.05$ se Acepta la Hipótesis Alternativa (Ha). En ese sentido, se presenta la matriz de correlación: 


\section{Journal of the Academy $|86|$}

\begin{tabular}{|c|c|c|c|}
\hline & & $\begin{array}{l}\text { GESTIÓN DE LOS } \\
\text { DIRECTIVOS }\end{array}$ & $\begin{array}{c}\text { CALIDAD DEL } \\
\text { SERVICIO EDUCATIVO }\end{array}$ \\
\hline \multirow{3}{*}{$\begin{array}{l}\text { GESTIÓN DE LOS } \\
\text { DIRECTIVOS }\end{array}$} & $\begin{array}{l}\text { Correlación de } \\
\text { Pearson }\end{array}$ & 1 &, $897^{* \prime}$ \\
\hline & Sig. (bilateral) & &, 000 \\
\hline & $\mathrm{N}$ & 333 & 333 \\
\hline \multirow{3}{*}{$\begin{array}{l}\text { CALIDAD DEL } \\
\text { SERVICIO } \\
\text { EDUCATIVO }\end{array}$} & $\begin{array}{l}\text { Correlación de } \\
\text { Pearson }\end{array}$ & ,897" & 1 \\
\hline & Sig. (bilateral) & ,000 & \\
\hline & $\mathrm{N}$ & 333 & 333 \\
\hline
\end{tabular}

Como el valor $\mathrm{p}=0.000<0.05$, se rechaza la hipótesis nula y se acepta la hipótesis alterna. Por lo tanto, la Gestión de los directivos se relaciona de manera significativa con la calidad del servicio educativo del colegio San Antonio Marianistas, asimismo la correlación es directa, significativa y alcanza un nivel de 0.897 que corresponde a un nivel de correlación positiva alta.

De la presente investigación ha consistido en demostrar como la gestión de los directivos se relaciona con la calidad del servicio educativo, ha permitido estudiar y demostrar a través de las dimensiones liderazgo directivo, planificación estratégica, evaluación de gestión y convivencia institucional en la primera variable y la calidad de los recursos del sistema, calidad de enseñanza, y calidad de los procesos y entornos de aprendizaje de la otra variable.

Martínez (2014) concluye que si existe una relación positiva entre evaluación de la gestión administrativa con la calidad educativa y los resultados obtenidos demuestran que, si existe relación positiva entre el talento humano con la calidad educativa, en un $23.8 \%$ de significancia.

De la misma forma, los resultados de la investigación ratificaron la hipótesis de que existe una relación positiva entre los recurso didácticos y físicos y la calidad educativa, en un $9.4 \%$ de significancia.

García (2009) los resultados obtenidos señalan que las actividades cotidianas del gestor escolar, impactan en la calidad educativa, se observó que la jornada laboral de los participantes es consumida más por la solución de problemas imprevistos que por actividades administrativas, dejando casi sin atención al factor pedagógico. 


\section{Journal of the Academy | $87 \mid$}

Concluye que las actividades que realizan los directores participantes, impactan en la calidad de su escuela, ya sea de forma positiva o negativa, pero siempre tienen una influencia.

Las conclusiones arribadas se complementan con la investigación realizada por Salas \& Lucín (2013) manifiestan que se debe incrementar la infraestructura física de la unidad educativa, incorporar la información del entorno familiar en la planificación del proceso educativo, propiciar que los docentes jóvenes se enriquezcan con la experiencia de los docentes de mayor trayectoria y estos se nutran de nuevos paradigmas.

Esta investigación se refuerza con la investigación realizada por Velásquez (2009), quien afirma que un $95 \%$ de probabilidad, que existe una relación directa y significativa entre el planeamiento estratégico y la calidad de servicio educativo en las IE. Publicas secundarias del distrito imperial, provincia de Cañete.

\section{CONCLUSIONES}

El estudio realizado ha demostrado que se relaciona significativamente la gestión de los directivos con la calidad del servicio educativo. Se considera que la presente investigación es un aporte que permita contribuir a futuras investigaciones y asimismo para que las autoridades de turno de la institución educativa, dispongan las medias necesarias para optimizar la gestión de los directivos que incide en la calidad del servicio educativo.

Asimismo, debe tenerse en cuenta el liderazgo de los directivos y de los miembros de la comunidad educativa por las de decisiones acertada, con la finalidad de garantizar el buen trabajo y servicio que brinda la institución educativa para el logro de los objetivos institucionales.

\section{Recomendaciones}

Se recomienda que es necesario tener en cuenta los procesos de la gestión del personal directivo mediante un estudio técnico científico siendo esta flexible y participativa para lograr una calidad de servicio educativo a toda la comunidad del colegio San Antonio Marianistas. Es importante contar con clientes internos y externos que evalúen la gestión semestralmente 


\section{Journal of the Academy $|88|$}

realizando planes de acción, de mejora, planes institucionales, estratégicos, planes curriculares con la participación de todos los actores de la comunidad educativa para lograr la calidad educativa.

\section{REFERENCIAS BIBLIOGRÁFICAS}

Arana, M. E. (1998). Principios y procesos de la Gestión Educativa. Printed

Alvarado, O. (1990). Gerencia Educativa. Universidad de Lima.

Asmat, W. (2004). Mejoramiento de la calidad en el servicio académico de un instituto de educación superior. http://sisbib.unmsm.edu.pe/Bibvirtual/Resultados_Busqueda.asp?q=educacion\%20Bib Virtual/monografias\&domains=sisbib.unmsm.edu.pe\&sitesearch=sisbib.unmsm.edu.pe .

Blejmar, B. (2015). Gestionar es hacer que las cosas sucedan, Ediciones Novedades Educativas - México.

Bolívar, A.; López, J. y Murillo, F.J. (2013) liderazgo en las instituciones educativas. Una revisión de líneas de investigación. Universidad de Granada. Revista Notas.

Cano, E. (1988). Educación de la calidad educativa. Edit. Muralla. Madrid. Colección aula abierta.

Casassus, J. (2000) Problemas de la gestión educativa en América Latina (la tensión entre los paradigmas de tipo A y el tipo B). Unesco.

Cardona, J. (1994) Metodología innovadora de evaluación de centros educativos. Madrid: Sanz y Torres S.L.

Colegio San Antonio Marianistas. Plan estratégico institucional. http://www.sanantonio.edu.pe/

Cuevas. R. (2011). Gerencia, gestión y liderazgo educativo. Editorial San Marcos - Perú.

Farro, F. (2001). Planeamiento estratégico para instituciones educativas de calidad. Udegraf. Perú

García, J. (2009). La gestión escolar como medio para lograr la calidad en instituciones públicas de educación primaria en Ensenada, Baja California. UNMSM

Gento Palacios, Samuel (2013) Relevancia del liderazgo de la dirección para la calidad de la institución educativa. Participación educativa, 2(2).

Gonzales María, Teresa (2003) Pearson-Prentice Hall Madrid. Organización y gestión de centros educativos. Dimensiones y procesos.

Hernández, S., Fernández, A. Baptista, A. (2014). Metodología de la Investigación. México. Editorial Mc Graw Hill. 


\section{Journal of the Academy | 89|}

Ley General de Educación, Ley No 28044.

Martínez, F. Evaluación De La Gestión Administrativa y su Influencia En La Calidad Educativa Del Colegio Militar No 10 “Abdon Calderón” A Nivel De Bachillerato En Periodo Lectivo 20113-2014. UNMSM

MINEDU. (2004). Innovando la gestión de las instituciones educativas. www.minedu.gob.pe

Mejía, E. (2005). Metodología de la Investigación Científica. Centro de Producción Editorial e Imprenta de la UNMSM.

Pérez, R. (1998). La evaluación externa y sus implicaciones: aspectos técnicos, prácticos y éticos. Revista de la Asociación de Inspectores de Educación de España.

Robinson, Lloyd y Rowe, (2008) El impacto del liderazgo en los resultados de los estudiantes: Un análisis de los efectos diferenciales de los tipos de liderazgo REICE. Revista Iberoamericana sobre Calidad, Eficacia y Cambio en Educación, 12(4), pp. 13-40.

Seibold. J. (2013) La calidad integral en educación: reflexiones sobre un nuevo concepto de calidad educativa que integre valores y equidad educativa. OAI.

Tafur, R. (1995). La Tesis Universitaria. La tesis doctoral, la tesis de maestría, el informe y la monografía. Primera Edición. Editorial Mantaro. Lima, Perú.

UNICEF- PREAL (2004). Escuelas efectivas en sectores de pobreza. Santiago de Chile: Ministerio de educación - Unicef. Benavides, M. (2000). Menezes-Filho, N. e Pazello, E. Santiago de Chile: PREAL.

Velásquez, T. (2009). "Planeamiento estratégico y calidad del servicio educativo en las I.E. públicas secundarias de Imperial - Cañete”. UNMSM 